\title{
Weblogues e jornalismo: um exemplo de aproximação na universidade portuguesa
}

Luís António Santos* e Fernando Zamith**

Este texto tem por objectivo a análise enquadrada de uma experiência de utilização de weblogues no desenvolvimento de competências profissionais no âmbito de uma licenciatura em Jornalismo e Ciências da Comunicação. Estando ainda por esclarecer se, de facto, os weblogues constituem um novo suporte híbrido ${ }^{1}$, o certo é que algumas das suas primeiras aplicações sugerem claros pontos de contacto com o vasto campo de acção do jornalismo, revelando-se também, desde já, um novo espectro de vantagens e um novo conjunto de questões potencialmente problemáticas. A experiência em curso na Universidade do Porto pode funcionar, em simultâneo, como um laboratório de novos métodos de ensino/aprendizagem e como repositório - ainda que embrionário e controlado - de alguns dos desafios que o jornalismo pode vir a enfrentar no futuro não muito distante.

Os weblogues são tão antigos como a Internet. O primeiro weblogue foi, simultaneamente, a primeira página web, desenvolvida, em 1990, por Tim Berners-Lee no Centro Europeu de Investigação Nuclear (CERN), uma vez que se tratava, sobretudo, de um registo automático de dados sobre o aparecimento de novos sítios. Até 1996, algumas páginas (como a 'What's new' da Netscape) foram assumindo esse mesmo papel de indicação muito pouco mediada de novidades na web. Ainda em 1996 começaram, no entanto, a surgir exemplos de espaços com muito maior mediação humana e especialmente vocacionados para iniciativas colaborativas e/ou comunitárias. Dave Winner, o autor do mais antigo weblogue ainda em existência, criou o seu 'Scripting News' em Janeiro de 1997 e experiências semelhantes de divulgação, seriação e classificação humana de conteúdos na Internet começaram a surgir com mais frequência nos anos seguintes. O crescimento foi tudo menos gradual e o ano de 1999 viria a conhecer a

\footnotetext{
* Foi jornalista do JN e da BBC (Secção Portuguesa). É docente de jornalismo de rádio e TV no Curso de Comunicação Social da Universidade do Minho (1santos@ics.uminho.pt).

** É jornalista da agência Lusa e docente de jornalismo digital no Curso de Jornalismo e Ciências da Comunicação da Universidade do Porto.

${ }^{1}$ Expressão usada por Eric Zorn no lançamento do weblogue do Chicago Tribune (18.08.2003), http://www.chicagotribune.com/news/columnists/ericzorn/chi-0308zornarchive.story (17.10.2003).
} 
primeira explosão de interesse; o aparecimento de ferramentas específicas, gratuitas e simples (Pitas, Blogger e Groksoup) encerrava, definitivamente, o breve período de tempo em que só os chamados entusiastas da web² podiam sentir-se tentados a integrar o grupo de bloggers $^{3}$. Em 2000 os weblogues já se contavam aos milhares e, três anos depois, a mais popular ferramenta, Blogger, anunciou, logo em Janeiro, ter atingido o primeiro milhão de utilizadores. Um estudo recente, desenvolvido pela Perseus, estima que até ao Verão de 2003 tenham sido criados 4,12 milhões de weblogues em todo o mundo, dos quais apenas 1,4 milhões são entendidos como activos (têm, pelo menos, uma actualização no espaço de dois meses $)^{4}$. A AOL começou a oferecer a possibilidade de 'blogar' aos seus clientes a partir de Agosto, ao mesmo tempo que a Yahoo fazia uma experiência-piloto similar no seu site coreano. Ambas as empresas seguiram os passos de dois outros gigantes, que abriram portas aos weblogues logo no início de 2003 - Google e Lycos. O interesse imediato, dada a gratuitidade dos serviços, terá começado por ser a fidelização de clientes, mas a perspectiva de uma utilização comercial estará, por certo, presente na elaboração da opção estratégica destas empresas. Um sinal emblemático do despertar desse interesse comercial pelos weblogues - e do eventual fim do 'carácter puritânico' da actividade, como escrevem os autores da AlwaysOn ${ }^{5}$ - terá sido a publicação, em meados de Agosto, de um artigo na secção 'Business' da conservadora revista britânica The Economist, com o título 'Blogging, to the horror of some, is trying to go commercial ${ }^{\circ 6}$.

Em Portugal, 2003 terá também sido o ano da grande (a uma outra escala) afirmação dos weblogues. A primeira tentativa consistente de elaborar uma listagem, iniciada em Janeiro, referenciava 174 entradas. Em Maio os weblogues portugueses eram já 400, em Junho mais de 600 e, no princípio de Julho, 9057. Neste momento não existe uma única listagem de todos os weblogues escritos por portugueses, sendo certo porém que deverão exceder já os dois milhares. O directório 'ptbLOGGERS', criado em Julho e com a aceitação de novas entradas suspensa, registava, no dia 17 de Outubro, 1442 weblogues ${ }^{8}$. Um outro directório, o 'Bloco-notas: Portuguese blogspotting', acolhia, na mesma data, referências da 2462 weblogues ${ }^{9}$ e um outro, o 'weblog.com.pt', incentivador da utilização da ferramenta Movable Type, registava 665 entradas $^{10}$. À seme-

\footnotetext{
${ }^{2}$ Pessoas que dominavam o código HTML e tinham já facilidade de criação da sua própria página.

${ }^{3}$ A página de Jesse James Garrett, contendo apenas indicações sobre weblogues, registava, no início de 1999, somente 23 entradas (Blood, 07.09.2000: 1).

${ }^{4}$ Perseus Development Corporation (03.10.2003). 'The Blogging Iceberg - Of 4.12 Million Hosted Weblogues, Most Little Seen, Quickly Abandoned’, White Paper. http://www.perseus.com/blogsurvey/ (17.10.2003).

${ }^{5}$ http://alwayson-network.com/printpage.php?id=840_0_2_0 (10.09.2003).

${ }^{6}$ The Economist (14.08.2003).

${ }^{7}$ Altura em que Pedro Fonseca anunciou ser-lhe impossível continuar com a tarefa. http://blogsempt.blogspot.com (17.10.2003).

${ }^{8}$ http://www.omeudiario.net/ptbloggers (17.10.2003).

${ }^{9}$ http://bloconotas.blogspot.com (17.10.2003).

${ }^{10}$ http://weblog.com.pt (17.10.2003).
} 
lhança do que aconteceu à escala internacional, também o maior motor de busca/ prestador de serviço nacional, o Sapo, passou a disponibilizar, a partir do início de Novembro, a possibilidade de criação de weblogues.

Se pensarmos nos 1,4 milhões de weblogues activos (e também nos cerca de dois mil portugueses) por comparação com o número de utilizadores da Internet (665 milhões, segundo uma antevisão da UNESCO para $2003^{11}$ ), não teremos dificuldade em aceitar a leitura forçosamente relativizadora subjacente às conclusões de um estudo recente da Forrester Research, segundo o qual, apenas dois por cento dos lares norte-americanos on-line visitam um weblogue mais do que uma vez por mês, sendo que 79 por cento das pessoas questionadas não ouviram sequer falar da blogosfera antes do inquérito ${ }^{12}$. Este tipo de dados ajuda-nos, certamente, a escutar com prudência quaisquer propostas de sobrevalorização da nova actividade, embora possa também ajudar a cimentar argumentos sobre o carácter passageiro da blogosfera e, por arrastamento, sobre a sua quase absoluta irrelevância. Sendo pacífico que 'blogar' é, apesar de tudo, uma actividade ainda muito restrita e sendo igualmente aceitável que, com toda a facilidade, se encontram exemplos de conteúdo muito pouco relevante ou original, parece-nos importante reter, a este propósito, a afirmação de Matt Welsh, segundo a qual '90 por cento de todas as novas formas de expressão tendem a ser medíocres'. 'Julgar um meio pelos seus piores elementos não é uma actividade muito louvável', adianta Welsh, para acrescentar: 'as acções dos que estão nos 10 por cento estão entre as coisas mais excitantes (...) vistas nos últimos tempos' (2003).

O debate sobre a relevância dos weblogues no contexto das tecnologias de comunicação e informação (ICT) continua ainda em aberto. Seja a blogosfera uma moda passageira, um arrufo de tecnofóbicos sem qualificações específicas, a utilização massificada de algo que não tem nada de novo, ou seja ela, pelo contrário, um alternativo meio de comunicação interpessoal, potenciador de novos espaços de debate público, criador de alterações profundas no entendimento que profissionais e destinatários têm de algumas áreas de actividade, cremos que, nesta fase, será muito mais proveitoso congelar juízos de valor em benefício da análise de acções/interacções concretas em curso.

\section{Um novo ambiente de trabalho}

Um olhar centrado nas características técnicas dos weblogues levar-nos-ia a descrevê-los como sítios web, criados, mantidos e actualizados com o mínimo recurso à utilização do código, capazes de suportar um arquivo e de incorporar ligações para outros endereços. Podem ser vistos como uma espécie de sistemas light de gestão de informação, com capacidade para capturar, organizar, manipular e aceder, em contí-

\footnotetext{
${ }^{11}$ http:// portal.unesco.org/ev (05.11.2003)

${ }^{12}$ Estudo realizado em Agosto de 2003 e referido em Kopytoff, V. (01.09.2003). 'Internet giants catch on to blogs - major portals provide services for online journals', in SFGate.com (San Francisco Chronicle). http://www.sfgate.com/cgi-bin/ article.cgi?file=/chronicle/archive/2003/09/01/BU307739.DTL\&type=tech (10.09.2003) .
} 
nuo e de forma simplificada, a todo o tipo de conteúdos. A conjugação de uma estrutura formal rígida como a possibilidade da abertura a uma míriade de conteúdos poderá ser uma das razões do seu grande sucesso, comportando-se aqui a blogosfera como uma espécie de um novo 'ambiente de trabalho', não já instalado no computador de cada um, mas disponível, para partilha, na web. Uma vez familiarizado com um weblogue, qualquer internauta pode, sem grande esforço, procurar informações num outro ou desenvolver o seu. Mesmo tendo em conta as especificidades das diferentes ferramentas disponíveis, a lógica subjacente ao formato é a mesma e o conforto que deriva dessa constância é, por certo, factor de simultânea tranquilização e de renovada confiança, tão necessárias à manutenção de um outro traço distintivo destas novas páginas web - a frequência de actualização. Embora este tema mereça, por certo, o olhar atento de outros que não nós, parece-nos que o novo 'ambiente de trabalho' - na tal rigidez facilitadora da interacção - vive fundamentalmente de uma estruturação da temporalidade. Todas as novas entradas são datadas e aparecem no weblogue em cronologia inversa, permitindo que um visitante leia sempre, em primeiro lugar, o post mais recente. Uma lógica semelhante preside ao armazenamento de informações mais antigas e à apresentação dos comentários (sejam ou não eles parte integrante da ferramenta original). Esta centralidade do tempo, sendo partilhada por uma comunidade de 'bloggers-leitores-de-blogs' terá certamente um efeito acelerador da frequência de actualização, levando mesmo a que já se fale numa 'angústia do post seguinte ${ }^{\text {13 }}$.

Um olhar centrado nas características técnicas não nos dá, no entanto, uma visão abrangente do fenómeno. Importa manter esse mesmo olhar atento aos efeitos que os weblogues produzem e, sobretudo, manter alguma disponibilidade para o que pode estar contido na surpresa. Numa entrevista dada a Giles Turnball no início de 2001 um dos criadores do Blogger, Evan Williams, admite que, para a própria equipa original (três pessoas), a forma como a blogosfera cresceu (e note-se que, nessa altura, o Blogger acolhia ainda apenas cerca de 118 mil utilizadores) forçou alterações de percepção. 'Gostava de afirmar que se tratou, desde o início, de puro génio, mas não foi isso que se passou. Pessoalmente, demorou-me bastante tempo a perceber o que tinham de tão significativo tanto o formato blogue como a nossa própria ferramenta', diz Williams, para quem a distintividade dos weblogues resulta da combinação de três factores: frequência, brevidade e personalidade (Turnball, 28.02.2001: Part 2).

Se os outros factores parecem ter sido responsáveis pela garantia de fundações sólidas à blogosfera parece-nos que terá sido aquilo que Williams descreve como 'personalidade' que lhe trouxe carácter, dinamismo, novidade e crescente apelo. A formalidade do modelo facilitou a chegada de muitos novos criadores de conteúdos à Internet mas foi essa quase ilimitada possibilidade de temáticas que os fixou aos weblogues e à sua lógica de funcionamento (incluindo a pressão da actualização). A ferramenta Blogger criou (de forma mais ou menos planeada) o ambiente propício ao aparecimento de um novo tipo de weblogue. O original 'weblogue-filtro' (com ou sem mediação humana)

\footnotetext{
${ }^{13}$ Expressão usada por João L. Nogueira, na apresentação da comunicação "Weblogues, cidadania electrónica e esfera pública" feita durante o I Encontro Nacional de Weblogues.
} 
passaria, de 1999 em diante, a ter por companhia o 'weblogue-bloco-de-apontamentos', o modelo que, ainda hoje, mais adeptos conquista para a blogosfera ${ }^{14}$. Os posts mais higienizados dos weblogues-filtros passaram a ter que partilhar o espaço com posts plenos de comentário pessoal, sobre temas tão variados como a culinária, a vida, a música, um autor em particular, o percurso para o emprego, ou uma cor, entre outros. 'Bloggers-leitores-de-blogs' cedo começaram a estabelecer ligações entre si, referenciando-se mutuamente mas, sobretudo, discutindo num weblogue um tema lido num outro. Estas ligações deram lugar a novas comunidades, com novos interesses, cuja principal vantagem - a potencialmente igual capacidade de participação de todos os elementos - não foi, até agora, empalidecida pela inevitável emergência de algumas 'figuras de culto'.

Será interessante convocar, a este propósito, a leitura que da blogosfera fazem Mortensen e Walker, como um substituto virtual do espaço do saloon (para a cultura norte-americana), do pub (na tradição anglófona), ou do café (numa leitura mais mediterrânica). Socorrendo-se das observações de Habermas sobre a esfera pública (e da visão desse espaço partilhado como um lugar onde não se observam as regras sociais do respeito pelo estatuto), escrevem que 'um blogue é escrito por um indivíduo e expressa a atitude e convicção do seu escritor; é estritamente subjectivo, embora não necessariamente íntimo. Isto não o impede de estar no domínio público e de se preocupar com questões que pertencem ao domínio da autoridade pública. Cada indivíduo pode usar os weblogues como entender melhor, sem respeito por qualquer tirania de valores que lhe imponha o que é ou não válido como tema de escrita ${ }^{615}$ (2002: 258).

O sucesso exponencial dos weblogues deve-se, fundamentalmente, a esta sua potencialidade de abertura a quem nunca antes teve possibilidade de avançar reflexões/comentários/informações para além do seu círculo restrito de conhecimentos pessoais. A 'publicação pessoal', conceito que já serviu para atrair as pessoas para a própria Internet, ganhou uma mais efectiva expressão. Os weblogues tornaram-se espaços alternativos de comunicação, onde cada um pode ter a tal 'voz' que tantas vezes lhe foi prometida. Sendo certo que poderá existir, na participação efectiva na blogosfera, tanto de projecção do ego como de voyeurismo, parece-nos não menos verdade que, apesar disso, as tais 'vozes' estão lá, no mais dos casos abertas à discussão e em todos eles disponíveis para escrutínio. Todos podemos, autonomamente, avaliar em contínuo a postura de qualquer outro blogger pela verificação das suas palavras passadas e das ligações referenciadas. Como nos diz Tim Jarrett, 'um blogger cria uma voz on-line com história, cronologia, evolução e contexto'. Mais importante ainda, adianta Jarrett, o acto de publicar num weblogue (por oposição a um documento privado) permite que outros escutem a tal 'voz': 'Se as palavras de um blogger são ouvidas e outros entram no diálogo, o blogger deixou de ser um observador passivo da Internet para se tornar num criador dela. Isto permite que pessoas - desde

\footnotetext{
${ }^{14}$ Blood, R. (07.09.2000). 'Weblogs: a history and perspective'. http://rebeccablood.net/essays/weblog_history.html (02.09.2003).

${ }^{15}$ Referência aos critérios de valoração noticiosa expressos por Galtung e Ruge. Galtung, G. e Holboe Ruge, M. (1965). 'The Structure of Foreign News', in Journal of Peace Reaserch, Bd. 2), 65-91.
} 
adolescentes confusos a programadores de software, a tradutores iraquianos em Bagdade e a avós com uma paixão pela política - que nunca tenham escrito um texto antes sejam lidos em todo o mundo ${ }^{16}$. Sendo aceitável que a asserção final da frase denota alguma fragilidade, sobretudo em face de um crescimento naturalmente desregrado e naturalmente pouco inventariado da blogosfera ${ }^{17}$, isso não põe em risco o seu principal ponto de ancoragem - os weblogues são espaços pessoais e interpretativos, marcados, em simultâneo, pela subjectividade e por um certo grau de responsabilização.

Parece-nos demasiado ambiciosa a ideia de que esta assunção de poder comunicacional por parte de um grupo crescente de 'utilizadores-tornados-criadores' da Internet apontaria no sentido de que se avançou já para uma cidadania mais participativa, em que a eliminação de algumas barreiras de definição valorativa de conteúdos (gatekeeping) alterou a unidireccionalidade dos fluxos e, por consequência, democratizou a informação. Parece-nos, por oposição, demasiado redutor focar atenções nas desvantagens de uma pulverização de conteúdos, nas fraquezas de uma postura 'amadora' dos novos criadores e ainda no carácter precoce de qualquer avaliação que retire demasiado peso à ainda esmagadora unidireccionalidade dos fluxos informativos. Não querendo correr o risco de desvalorizar liminarmente estas duas visões antagónicas, torna-se inevitável transcrever aqui o que sobre o assunto disse Walter Shapiro, colunista do USA Today: 'Como qualquer outra revolução, a blogosfera é exageradamente promovida na fase de crescimento, exageradamente depreciada na fase seguinte e finalmente assenta, no reino intermédio da realidade ${ }^{618}$.

Aceitando que muito do que se produz nos weblogues é ainda reactivo - seja comentário, opinião, ou até mesmo apresentação de novos factos que contrariem algo inicialmente dado a conhecer através de um dos canais de comunicação mais tradicionais -, parece-nos claro que a blogosfera se afirma, sobretudo, por ser um espaço de ruptura: há lugar para ideias mais marginais (sobretudo porque a ideia é, ainda assim, mais valorada do que a sua fonte), há sinais de um novo processo de criação de conhecimento partilhado, há uma maior descentralização na produção e distribuição de conteúdos e há uma reformulação das concepções tradicionais sobre audiência/destinatário/receptor.

\section{Weblogues e jornalismo}

O aparecimento e expansão da Internet, no final do século passado, forçaram o jornalismo convencional a repensar processos de recolha e de produção de informação. Cedo se percebeu o carácter revolucionário da web - permitia juntar texto, imagens, gráficos, animação, áudio, vídeo e entregá-los aos destinatário em tempo real - mas demorou mais algum tempo a apreender o impacto do novo leque de potencialidades -

\footnotetext{
${ }^{16}$ Post publicado no "Jarrett House North" sob o título 'Blogs providing voices'. http://discuss.jarretthousenorth.com/ 2003/10/10?print-friendly=true

${ }^{17}$ Apesar de alguns esforços, como é o caso do recente motor de busca bloogz (www.bloogz.com).

${ }^{18}$ Citado por Chris Mooney no post-gazett.com (02.02.2003).
} 
interactividade, acesso personalizado e, sobretudo, mudança no perfil do utilizador, que poderia agora também partilhar a produção.

Nos primeiros anos da 'corrida à net' as empresas de comunicação social preocuparam-se muito mais com a ocupação de um lugar num meio que desconheciam do que com a adaptação dos seus conteúdos a esse mesmo meio. O sucesso de algumas experiências autónomas em páginas web tradicionais foi entendido como não mais do que uma ligeira ameaça, uma vez que o campo de acção, a linguagem e os processos de produção informativa destes novos actores continuavam a estar enquadrados no espaço vital dos meios mais tradicionais. Os jornalistas, por seu lado, começaram a aproveitar as vantagens do jornalismo assistido por computador, mas mantiveram, no essencial, a mesma relação com a sua audiência (que, na verdade, não era entendida como sendo muito diferente da que tinha o órgão de comunicação tradicional).

O surgimento do weblogue-bloco-de-apontamento cedo chamou a atenção de um grupo heterogéneo mas ainda restrito de utilizadores, onde se incluíam jornalistas profissionais mais atentos, leitores críticos da postura ideológica dos media tradicionais, académicos ligados à comunicação e alguns jovens com formação na área mas ainda em início de carreira. Os acontecimentos do dia 11 de Setembro de 2001 vieram alterar tanto a notoriedade desta nova forma de tratar informação como o seu ritmo de propagação. Perante a insatisfatória reacção dos meios tradicionais - se entendida à luz de uma nova percepção social da temporalidade, sem dúvida exacerbada em tempos de crise, em que a instantaneidade da transmissão por vezes vale mais do que a própria mensagem em si - os weblogues-jornais entraram, de supetão, na idade adulta. Só na blogosfera foi possível, para muitos, satisfazer um desejo permanente de 'actualização', capaz de canalizar um fluxo invulgar de novos desenvolvimentos, rumores, imagens, reacções e comentários. Os weblogues-jornais terão também funcionado como uma (mais uma) expressão catártica de sentimentos, sedimentando assim um estilo muito próprio, já comum e perfeitamente pacífico noutros weblogues, mas profundamente perturbador para o jornalismo estabelecido.

Esta explosão dos weblogues-jornais terá funcionado, para o jornalismo, como o primeiro de uma série de catalisadores de uma mudança que se impunha, mas que não havia ainda acontecido. O facto de se apresentar a hipótese de que alguns weblogues poderiam ser, eles próprios, uma nova forma de jornalismo tornou-se, por si só, indicativo do grau de distúrbio que a blogosfera trouxe ao ordenamento mediático pré-estabelecido. No auge da excitação com esta nova forma de tratar os conteúdos informativos, John V. Pavlik escrevia que 'a nova forma de jornalismo' se distinguia das restantes pelo seu carácter ubíquo, pelo acesso globalizado, pela instantaneidade, pela interactividade, pelo conteúdo multimédia e por uma personalização extrema: 'Em muitos sentidos, representa uma melhor forma de jornalismo porque consegue renovar a ligação a uma audiência cada vez mais desconfiada e alienada, mas, ao mesmo tempo, apresenta-se como uma ameaça aos valores e padrões de comportamento mais defendidos; autenticidade de conteúdo, verificação de fontes, correcção e verdade estão todas sob suspeita num meio em que qualquer pessoa com um computador e um modem se transforma num editor à escala mundial' (2001: 5). A discus- 
são cedo se tornou num exercício de defesa, por parte de alguns jornalistas, sobre o que constitui verdadeiro jornalismo e sobre quem pode ou não legitimamente intitularse jornalista. Precisamente aquilo que havia tornado tão populares os weblogues era o que mais se prestava a ataque nesta não-conversa; a ausência de qualquer processo editorial de filtragem de erros, de clarificação de linguagem e de confirmação de factos mencionados tornava os weblogues-jornais mais atraentes mas, simultaneamente, fragilizava-os à luz da visão mais consensual sobre o jornalismo.

O aceso debate a propósito dos weblogues-jornais poderá ter-nos dado uma indicação de que a dúvida expressa por Kovach e Rosenstiel, sobre se um jornalismo independente sobreviveria no novo século (2001: 13), está mais perto de uma resposta positiva, mas falhou, em absoluto, no alvo. Podendo os weblogues-jornais vir a ser, de facto, um espaço alternativo de um diferente tipo de jornalismo - chamando-se ele 'amador', 'comunitário' ou, simplesmente, 'participativo' - importará não tanto assegurar a sua conformidade com enquadramentos eventualmente desajustados à realidade presente mas antes - como parecem sugerir ainda Kovach e Rosenstiel - garantirlhes a autonomia suficiente para escapar a uma ameaça estrutural, 'o comercialismo comprometido que se faz passar por informação'(ibid.).

Para já, os weblogues-jornais - que nem sequer têm ainda expressão suficiente em Portugal - não são muito mais do que um útil complemento do jornalismo tradicional. Aquilo que J. D. Lasica considera o 'ground zero' da revolução da publicação pessoal via web (18.04.2002) terá garantido que o jornalismo iniciasse um percurso de actualização, tanto no estilo de apresentação como na postura perante a sociedade. Os bloggers (que são também leitores/ouvintes/telespectadores) questionam formas de actuar, perspectivas, apontam falhas, avançam alternativas e levantam novas dúvidas. Isso, se entendido por todos os jornalistas como uma oportunidade para produzir trabalho mais honesto, consistente e em contacto com as pessoas, pode dar-nos uma indicação mais correcta do eventual novo caminho do jornalismo. E se a história desta profissão, que - na feliz imagem de Kovach e Rosentiel - ajuda indivíduos e sociedades a manter alimentado o ‘instinto de percepção’ reservar aos weblogues o papel de propiciadores dessa mudança, isso já terá sido mais do que eventualmente preconizaram os seus primeiros utilizadores.

\section{Weblogues e ensino do jornalismo}

No seu texto 'How to write a better weblog', Dennis A. Mahoney começa por nos falar da clara diferença entre o profissional da escrita e o amador com um exemplo muito poderoso: um profissional diria «Nova Iorque é magnífica na Primavera», ao passo que um amador escreveria: "Sei que, hoje em dia, isto é um cliché, particularmente depois do 11 de Setembro, mas vivo em Nova Iorque, uma cidade que está agora muito mais limpa e segura por causa do Giuliani, que deveria, de facto, voltar a ser presidente, sobretudo depois de ter lidado tão bem com a crise (...) mas, depois de tudo dito e feito, Nova Iorque é uma grande cidade, especialmente quando come- 
ça a ficar mais quente e as pessoas começam a passar mais tempo fora de casa, como acontece em Março e Abril» (22.02.2002). A imagem é forte e deve, na nossa opinião, ser entendida muito para além das considerações sobre estrutura de texto e gramática. A frase, naturalmente caricatural, afirma, de forma muito simples, o espaço dos weblogues como a tal nova área de expressão pessoal e social e, por arrastamento, faz dos weblogues-jornais mais tradutores de um desejo de mudança de postura do jornalismo do que a afirmação conseguida de um corte radical com as formas tradicionais de exercer a profissão.

Parece-nos que será neste enquadramento não exagerado, de abertura ao novo sem perder de vista a essência do antigo, que os weblogues podem, gradualmente, proporcionar a jornalistas em formação um ambiente privilegiado de aprendizagem. É inegável que, pelo seu baixo custo, flexibilidade e natural enquadramento com as exigências do tempo jornalístico, os weblogues constituem uma excelente ferramenta para a prática de técnicas de expressão jornalística on-line: têm campos distintos para título, leadl entrada e corpo da notícia; permitem hipertexto e hipermédia; ordenam/destacam as notícias pelo critério mais adequado ao meio - a actualidade; criam automaticamente arquivos e categorias (por datas e temas); a publicação é imediata.

Ciente desta oportunidade, o curso de Jornalismo e Ciências da Comunicação da Universidade do Porto (a mais nova licenciatura pública na área e uma das que mais aposta nas vertentes prática e tecnológica) criou no início do ano lectivo de 2002/2003 um weblogue de apoio às aulas de Técnicas de Expressão Jornalística (TEJ) On-line, o JornalismoPortoNet (http://blog.icicom.up.pt ${ }^{19}$. Foi, talvez, um dos primeiros blogues portugueses a utilizar o Movable Type, ferramenta que, além de algumas funções novas, introduziu uma 'lufada de ar fresco' numa blogosfera já então algo saturada de páginas blogger muito iguais que apenas se distinguiam pelos títulos. Um dos docentes do curso, Sérgio Nunes, preparou o 'esqueleto' do blogue, fazendo algumas alterações ao esquema-base, nomeadamente a supressão do calendário, a introdução de novas categorias e, mais tarde, a tradução para português. O JornalismoPortoNet (ou JPN) rapidamente cumpriu as funções para que foi criado, funcionando como uma 'página inicial' das aulas de TEJ/On-line dos $2 .^{\circ}$ e $3 .^{\circ}$ anos, com informações úteis para os alunos, ligações a páginas de interesse para futuros jornalistas e 'local' de prática jornalística. O JPN e os 'weblogues-satélites' (de que falaremos adiante) deram visibilidade ao trabalho de alunos que, de outro modo, ficaria a ganhar pó numa qualquer prateleira de um escritório, biblioteca ou arquivo universitário.

Em Dezembro de 2002, uma experiência de redacção virtual realizada pelos alunos do 3. ${ }^{\circ}$ ano (http://www.icicom.up.pt/blog/ljcc/archives/000111.html\#000111) mereceu entradas em alguns weblogues especializados, nomeadamente nas versões on-line e em papel (Público) do Ponto Media (http://ciberjornalismo.com/arquivo/2002/ 2002_12_08_arquivo.htm). A experiência e a visibilidade obtidas, não só entusiasmaram os alunos, como reforçaram a consciência que já tinham das enormes potencialidades

\footnotetext{
${ }^{19}$ Uma outra experiência, com um diferente formato, foi iniciada no mesmo ano lectivo na Universidade do Minho, o Aula de Jornalismo.
} 
deste novo meio, ainda hoje pouco exploradas, sobretudo em Portugal. Paralelamente ao JPN, foram criados pelos alunos do $2 .^{\circ}$ ano três blogues (um por turma), com o objectivo de funcionarem como experiências de blog-jornais: Arte_Factos (http:// www.icicom.up.pt/blog/artefactos), Oubelá.com (http://www.icicom.up.pt/blog/ oubela) e Palco (http://www.icicom.up.pt/blog/palco). Estes 'weblogues-satélites', com nomes e grafismos escolhidos pelos alunos, foram alimentados exclusivamente com peças jornalísticas (feitas pelos alunos e editadas pelo jornalista/professor), nomeadamente entrevistas e pequenas notícias ou comentários (de exposições ou espectáculos vistos pelos alunos) sobre temas relacionados com cultura e lazer.

\begin{tabular}{|l|c|c|c|}
\hline Nome & Início & Entradas/posts & Comentários \\
\hline JornalismoPortoNet & Out./2002 & 206 & 44 \\
\hline Arte_Factos & Nov./2002 & 37 & 72 \\
\hline Oubelá.com & Nov./2002 & 39 & 22 \\
\hline Palco & Nov./2002 & 34 & 51 \\
\hline A Tenda dos Índios & Jul./2003 & 30 & 13 \\
\hline
\end{tabular}

A actividade destes três blogues foi muito 'sazonal', com quase todas as entradas a coincidirem com o período lectivo do primeiro semestre, ainda que tivesse havido um apelo aos alunos para que continuassem a alimentar os blogues no segundo semestre, o que apenas aconteceu esporadicamente. Este risco (assumido) de previsível paralisação dos blogues nunca foi entendido como um mal em si, dado tratar-se de trabalho em 'laboratório'. Despoletaram, contudo, uma série de alterações, para o ano lectivo de 2003/2004, como a concentração de produção em apenas dois ou três blogues temáticos.

Apesar de todos estes condicionalismos, os blogues do curso foram bastante visitados e até comentados. Os três ‘blogues-satélites' ficaram listados logo na primeira relação de 150 Blogsempt, o que contribuiu muito para essa visibilidade. Com 72 comentários, o Arte_Factos foi, na altura, o mais comentado, o que poderá ser explicado por três factores: nome extremamente bem conseguido; destaque que teve no Blogsempt dado esta lista surgir por ordem alfabética; interesse suscitado por algumas notícias, nomeadamente a entrevista a um professor de capoeira, que originou um vivo debate, registado em 16 comentários.

No segundo semestre, passaram pelo JPN outras experiências, necessariamente menos ambiciosas, de alunos do $1 .^{\circ}$ ano, que rapidamente ficaram com o 'bichinho' dos blogues, criando, autonomamente, várias páginas pessoais ou de pequenos grupos de dois ou três autores (http://www.icicom.up.pt/blog/ljcc/archives/000409.html\#000409). No final do semestre, a experiência alargou-se aos fotologues (http://www.fotolog.net), com os alunos a criarem inúmeras páginas de fotografias, algumas delas ainda activas.

Com estas experiências, alcançou-se o objectivo principal da disciplina, que seria a aplicação prática de noções teóricas sobre esta nova forma de fazer jornalismo: o treino da rapidez, da capacidade de síntese, da construção de notícias segundo a técnica dos blocos (pequenos textos ligados entre si) e do uso adequado do hipertexto. Promove- 
ram--se competências específicas do jornalismo num novo enquadramento, ao mesmo tempo atraente e recompensador para os jornalistas em formação.

$\mathrm{O}$ contacto permanente e continuado com os problemas que se põem diariamente à generalidade dos jornalistas - verificação, equilíbrio, correcção, independência - foi complementado pela pressão da observação constante não só dos docentes mas, sobretudo, dos seus pares. Ainda que num ambiente restrito, esta pressão e os efeitos que produz (a reformulação de trabalhos, a reconfirmação de factos, a abertura de novas linhas de acção) terá conseguido, pensamos, replicar de forma mais realista o ambiente de trabalho que muitos deles irão encontrar.

Da experiência em curso - que, a partir de 22 de Março de 2004, passou a ter outra expressão com o portal 'JornalismoPortoNet' (http://jpn.icicom.up.pt) - resulta claro que, ao invés de um desvio para o comentário adornado de factos (algo que aproveitam para fazer nos inúmeros weblogues pessoais que foram, entretanto, criando), estes jornalistas em formação parecem optar por uma apresentação o mais cuidada possível das situações, cientes que estão do grau de exigência de um escrutínio P2P. A mesmo exigência aguça o seu pensamento crítico e a busca de informações/perspectivas adicionais sobre um tema em tratamento. Se quisermos usar uma imagem já referida no texto, o processo editorial pode ser menos rigoroso e ter menos etapas (permitindo, assim, ao texto jornalístico maior liberdade e, eventualmente, maior contacto com a consciência pessoal do jornalista) mas isso poderá significar apenas que os mecanismos de controlo passaram a estar a jusante da produção informativa. Será mais fácil exigir maior honestidade, maior inquietação, maior adaptabilidade a uma sociedade em mudança e maior empenho em trabalho colaborativo aos jornalistas - talvez sim. Mas isso não nos parece, de todo, um indicador de fragilização do papel do jornalismo.

\section{Bibliografia}

Always On (10.09.2003). 'The Economist on Weblogs'. http://alwayson-network.com printpage.php?id=840_0_2_0 (10.09.2003).

Amelan, R. (October 2003). 'Communication: From information society to knowledge society', in The New Courier, n’3. UNESCO. http://portal.unesco.org/ev (05.11.2003).

Ashley, C. (2002). 'Weblogs, part II: A Swiss Army website?'. http://istpub.berkeley.edu:4201/bcc/Winter2002/feat.weblogueging2.html

Ashley, C. (2001). 'Weblogging: Another kind of website'. http://istpub.berkeley.edu:4201/bcc/Fall2001/feat.weblogueging.html

Blood, R. (2003). 'Weblogs and Journalism: Do They Connect?', in Nieman Reports, Vol. 57, n. ${ }^{\circ}$, Fall 2003. Cambridge MA: Nieman Foundation at Harvard University.

Blood, R. (07.09.2000). 'Weblogs: a history and perspective'. http://rebeccablood.net/essays/weblogue_history.html (02.09.2003).

Fonseca, P. (23.09.2003). 'Blogues e jornalismo: do produtor ao consumidor', comunicação apresentada durante o 'I Encontro Nacional sobre Weblogues'(18-19.09.2003). Braga: Universidade do Minho. http://cecinestpasunblog.blogspot.com/ (17.10.2003).

Grumet, A. (05.2003). 'Deep Thinking about Weblogs'.

http://grumet.net/writing/web/deep-thinking-about-weblogs.html (02.09.2003). 
Hall, J. (2001). On-line Journalism - A Critical Primer, London: Pluto Press.

Hiler, J. (11.04.2002). 'Are Bloggers Journalists?', in microcontentnew.com. http://www.microcontentnews.com/articles/bloggingjournalism.htm (01.07.2003).

Hiler, J. (28.05.2002). 'Blogosphere: the emerging media ecosystem', in microcontentnew.com. http://www.microcontentnews.com/articles/blogosphere.htm (19.10.2003).

Hiler, J. (20.06.2002). 'Blogs as Disruptive Tech', in WebCrimson. http://www.webcrimson.com/ourstories/blogsdisruptivetech.htm (12.06.2003).

Jarrett, T. (10.10.2003). 'Blogs providing voices' in Jarrett House North. http://discuss.jarretthousenorth.com/2003/10/10?print-friendly=true (02.11.2003).

Jensen, M. (2003). 'A Brief History of Weblogs', in Columbia Journalism Review, $\mathrm{n}^{\circ}$ 5, Setembro/Outubro. http://www.cjr.org/issues/2003/5/blog-jensen.asp?printerfriendly=yes (18.10.2003).

Kopytoff, V. (01.09.2003). 'Internet giants catch on to blogs - major portals provide services for on-line journals', in SFGate.com (San Francisco Chronicle). http:/www.sfgate.com/cgi-bin/article.cgi?file=/ chronicle/archive/2003/09/01/BU307739.DTL\&type=tech (10.09.2003).

Kovach, B. \& Rosenstiel, T. (2001). The elements of journalism: what newspeople should know and the public should expect. New York: Three Rivers Press.

Lasica, J. D. (ed.) (2003). 'We Media - How audiences are shaping the future of news and information' (Thinking paper). Reston, Va: The Media Center at the American Press Institute.

Lasica, J. D. (31.05.2002). 'Weblogs: a new source of news', in On-line Journalism Review. http://www.ojr.org/ojr/workplace/1017958782.php (22.10.2003).

Lasica, J. D. (18.04.2002). 'Blogging as a form of Journalism', in On-line Journalism Review. http://www.ojr.org/ojr/lasica/1019166956.php (22.10.2003).

Lima, T. (07.2003). 'O mundo paralelo dos weblogues', umjornal, $\mathrm{n}^{\circ} 5$.

Livingston, N. (26.09.2002). 'Weblogs, The Future of Education?'. http://www.geocities.com/nlivingston_99/Weblog.htm (12.06.2003).

Mahoney, D. A. (22.02.2002). 'How to write a better weblog'. http://www.alistapart.com/stories/writebetter/ (28.02.2003).

Mooney, Ch. (02.02.2003). 'How blogging changed journalism - almost', in post-gazette.com (05.03.2003).

Mortensen, T. \& Walker, J. (2002). 'Blogging thoughts: personal publication as an on-line research tool', in Morrison, A. (ed.) (2002), Researching ICT's in Context, Oslo: InterMedia Report. http://www.intermedia.uio.no/konferanser/skikt-02/docs/Researching_ICTs_in_context-Ch11-MortensenWalker.pdf

Nogueira, J. L. (2003). 'Weblogues, Cidadania electrónica e esfera pública', comunicação apresentada durante o 'I Encontro Nacional sobre Weblogues'(18-19.09.2003), Braga: Universidade do Minho.

Pavlik, J. V. (2001). Journalism and New Media, Columbia University Press.

Pinto, M. (2003). 'Um potencial de enriquecimento da vida pública', in Granado, A. \& Barbosa, E. (2003). Weblogs: Um diário de bordo, Porto: Porto Editora.

Quinn, S. (1999). 'Teaching journalism in the information age', in Australian Studies in Journalism, 8, pp. $158-175$.

Rosen, J. (2003). 'Readers and Viewers - Rich Now in Alternative Sources of News - Are More Assertive and Far Less in Awe of the Press', in Columbia Journalism Review, n. ${ }^{\circ}$ 5, Setembro/Outubro. http://www.cjr.org/issues/2003/5/alt-rosen.asp?printerfriendly=yes (18.10.2003).

Shachtman, N. (06.06.2002). 'Blogging Goes Legit, Sort Of', in Wired. http://www.wired.com/news/school/0,1383,52992,00.html (12.06.2003).

Siemens, G. (01.12.2002). 'The Art of Blogging - Part 1', www.elearnspace.com (05.03.2003).

The Economist (14.08.2003). 'Blogging, to the horror of some, is trying to go commercial'. http://www.economist.com/printedidition/PrinterFriendly.cfm?story_ID=1994135 (10.09.2003).

Turnball, G. (28.02.2001). 'The state of the blog', WriteTheWeb. http://writetheweb.com/Members/gilest/old/107/view (12.11.2003). 
Tweney, D. (14.02.2002). 'Weblogs make the Web Work for You', Business 2.0.

http://www.business2.com/articles/web/print/0,1650,37974,FF.html (28.02.2003).

Weinberger, D. (2002). Small Pieces Loosely Joined - a unified theory of the web. Cambridge, MA: Perseus Publishing.

Welsh, M. (2003). 'The New Amateur Journalists Weight In', in Columbia Journalism Review, n⿳05, Setembro/ Outubro. http://www.cjr.org/issues/2003/5/blog-welsh.asp?printerfriendly=yes (18.10.2003).

Winer, D. 'The History of Weblogs'. http://newhome.weblogues.com/historyOfWeblogues (28.07.2003).

Zamith, F. (19.09.2003). 'Blog-Jornais: as experiências da Universidade do Porto', comunicação apresentada durante o 'I Encontro Nacional sobre Weblogues' (18-19.09.2003). Braga: Universidade do Minho.

\section{Weblogues portugueses consultados}

www.webjornal.blogspot.com (Jornalismo e Comunicação)

www.webjornalismo.blogspot.com (Jornalismo Digital)

www.ciberjornalismo.com/pontomedia.htm (Ponto Media)

www.contrafactos.blogspot.com (Contra Factos e Argumentos)

\section{Resumo}

Este texto propõe-se fazer uma primeira análise enquadrada de uma experiência de utilização dos weblogues como potenciadores da experiência profissionalizante no âmbito de uma licenciatura em Jornalismo e Ciências da Comunicação. Escapando a posições absolutamente estanques tanto sobre a natureza dos weblogues como sobre a sua relação com o jornalismo, os autores optam por salientar os pontos de sucesso da experiência e por indicar que a possibilidade de uma real diminuição do controlo editorial da produção informativa pode significar apenas que alguns dos mecanismos tradicionais passam a existir já a jusante do processo.

\section{Abstract}

The purpose of this text is to present a reading of a weblog use experience in the context of a Journalism course. Intending to avoid any firm standing on such volatile areas as the nature of weblogs and its links with Journalism the authors rather choose to point out the virtues of the experience itself. The assertion is made that diminishing editorial control might simply mean that some of its mechanisms have been transferred elsewhere rather than having disappeared. 